\title{
BMJ Open Variability in potentially preventable hospitalisations: an observational study of clinical practice patterns of general practitioners and care outcomes in the Basque Country (Spain)
}

\author{
Juan F Orueta, ${ }^{1}$ Arturo García-Alvarez, ${ }^{2}$ Gonzalo Grandes, ${ }^{2}$ Roberto Nuño-Solinís ${ }^{3}$
}

To cite: Orueta JF, GarcíaAlvarez A, Grandes G, et al. Variability in potentially preventable hospitalisations: an observational study of clinical practice patterns of general practitioners and care outcomes in the Basque Country (Spain). BMJ Open 2015;5:e007360.

doi:10.1136/bmjopen-2014007360

- Prepublication history for this paper is available online. To view these files please visit the journal online (http://dx.doi.org/10.1136/ bmjopen-2014-007360).

Received 2 December 2014 Revised 20 March 2015 Accepted 25 March 2015

\section{CrossMark}

${ }^{1}$ Head of Centro de Salud de Astrabudua (Primary Health Care Center of Astrabudua), Osakidetza (Basque Health Service), Erandio, Bizkaia, Spain

${ }^{2}$ Primary Care Research UnitBizkaia, Osakidetza, Bilbao, Spain

${ }^{3}$ Deusto Business School Health, University of Deusto, Bilbao, Spain

Correspondence to Dr Juan F Orueta; jon.orueta@osakidetza.net

\section{ABSTRACT}

Objectives: To explain the variability in the frequency of potentially preventable hospitalisations (ambulatory care sensitive conditions, ACSCs) based on factors at multiple levels (individual, health professional, health centre and health district), and specifically using resource efficiency indicators for general practitioners (GPs).

Design: Cross-sectional study. We analysed primary care electronic health records and hospital discharge data using multilevel mixed models.

Setting: Primary care network of the Basque Health Service (Spain).

Participants: All the residents in the Basque Country $\geq 14$ years of age, covered by the public healthcare system ( $n=1959682)$, and all the GPs ( $n=1193)$ and health centres $(n=130)$.

Main outcome measures: Individuals admitted for ACSCs, over a 12- month period.

Results: Admissions for ACSCs were less frequent among patients who were female, middle-aged or from the highest socioeconomic classes. The health centre variables considered and GP list size were not found to be significant. After adjusting for the variables studied including morbidity, the risk of hospital admission was higher among individuals under the care of GPs with greater than expected numbers of patient visits and prescribing costs ( $\mathrm{OR}=1.27(95 \% \mathrm{Cl} 1.18$ to 1.37$) ; 1.16$ (1.08 to 1.25)), and who make fewer referrals than the mean among their colleagues ( $\mathrm{OR}=1.33$ (1.22 to 1.44)).

Conclusions: When assessing activities and procedure indicators in primary care, we should also define outcome-based criteria. Specifically, GPs who are repeatedly visited by their patients, have higher prescribing costs and are more reluctant to refer patients to specialists obtain poorer outcomes.

\section{INTRODUCTION}

Healthcare organisations often analyse variations in physician practice patterns for monitoring the quality and efficiency of primary care health services. In this way, it is assessed whether the use of healthcare resources by

\section{Strengths and limitations of this study}

- The main strength of this study is that we analysed data for an entire healthcare system, providing near universal care for the population of a defined geographical area.

- It assesses the relationship between preventable diseases and variables at different levels, ranked in accordance with the hierarchical nature of the data, as well as compares the risk of admission of patients seen by doctors with different clinical practice patterns.

- We used a robust system for adjusting for patient morbidity (the Johns Hopkins Adjusted Clinical Group case-mix system).

- The observational design of the study prevented us from ascribing causality to the associations observed.

- There are factors unrelated to primary care itself (such as variation in outpatient specialised care quality or hospital admission criteria) that could have an effect on hospital admissions. Also, characteristics other than the ones studied have an effect on the need for healthcare and its outcomes.

health professionals is what would be expected as a function of the morbidity in the population served. This information is very important: it allows physicians themselves to reflect on their own way of working and managers to identify health professionals with markedly different patterns of resource use from those of their colleagues.

It is widely agreed that some prescriptions, referrals to specialised care, requests for ancillary tests and primary care visits are not justified, ${ }^{1}$ and hence it could be argued that the rates of all of these should be reduced. However, analysing each indicator separately makes it difficult to reach conclusions: we should not assert that a general practitioner's 
(GP's) use of resources is excessive (or insufficient) without assessing their patient's outcomes. For example, situations of apparent efficiency may in reality be a failure to provide the necessary care to certain groups of patients resulting from lack of accessibility or poor clinical practice. In fact, numerous studies have indicated that a lower use of primary care resources is associated with adverse effects on the health of the population, ${ }^{2}{ }^{3}$ and certain attempts in the USA to reduce the number of ambulatory visits, ${ }^{4}$ through the introduction of copayments, may have a negative impact in terms of people's health. The effects of decreasing spending on prescriptions are also not fully known and a lack of association between quality and costs of prescribing has been reported. ${ }^{5}$ Although in some cases (such as the excessive use of antibiotics) the need for cutting back is unquestionable, ${ }^{6} 7$ in other cases, such a reduction may have unintended consequences. In relation to this, some authors have observed an inverse correlation between the number of prescriptions and hospitalisation costs, ${ }^{8}$ and that the use of disincentives for prescribing such as a copayment may lead to discontinuation of treatments by chronic patients and worsening of the health of vulnerable populations. ${ }^{9}$ As a result, to assess physicians in a fair manner and promote changes in clinical practice patterns with the goal of improving healthcare efficiency, we must take into account the impact of the care provided on outcomes.

In this context, an accepted method for assessing outcomes is to consider ambulatory care sensitive conditions (ACSCs). ${ }^{10}$ These are a series of conditions for which it should be possible to avoid hospital admission by providing timely and effective ambulatory care, through the following types of interventions: prevention at the primary care level, early diagnosis and treatment of acute diseases, and adequate control and follow-up of chronic diseases. Although based on hospital discharge reports, data on admissions for ACSCs provide us with indirect information regarding primary care, particularly accessibility of this level of care and its ability to resolve health problems. In America, ACSCs have mainly been used to measure access, while in other countries with national health services they have principally been used to assess quality of care. ${ }^{11}$ In any case, factors unrelated to primary care also influence hospital admissions, meaning that this instrument needs to be adapted to the context in which it is to be applied. ${ }^{11}$ For this reason, in our study we used lists of ACSCs that have been established for Spanish populations ${ }^{12}$ and have already been used by other authors. ${ }^{13-15}$

Numerous studies have indicated differences in ACSC admission rates as a function of the demographic, ${ }^{16}$ clinical $^{1718}$ and social ${ }^{15} 1920$ characteristics of patients. In addition, the rate has been found to be associated with factors attributable to healthcare systems and organisations. ${ }^{3}{ }^{21}$ However, few studies have analysed its relationship with factors related to GPs and, to the best of our knowledge, none have explored their way of working and clinical practice patterns. In this context, the objective of this study was to explain the variability in the rate of potentially preventable hospitalisations (ie, admissions for ACSCs) based on multilevel characteristics and factors (individual, health professional, health centre and health district) and, in particular, considering indicators of the efficiency of resource use by GPs.

\section{METHODS}

This was a cross-sectional study analysing the outcomes of the public primary care network for a 1-year period (2007/2008, Basque Country, Spain).

\section{Setting}

The Government of the Basque Country has been responsible for the planning and provision of healthcare services for the population in this region since 1983. Public healthcare provision is delivered by the Basque Health Service (Osakidetza), a public organisation funded through taxes that provides nearly universal care to residents in the region. Care is free at the point of delivery, except for prescriptions, for which there is copayment that varies depending on the type of disease and patient status (with exemptions for those who are retired or disabled, among others).

When this study was conducted, primary care health services in our setting were organised into seven health districts, corresponding to geographical areas. The primary care health districts are economically, financially and administratively independent and are funded by annual contracts with the Health Department of the Government of the Basque Country. Each of these districts has 9-22 health centres.

Primary care health professionals work in care teams. At the individual level, every resident is on the list of a GP, who is a family doctor or paediatrician depending on the patient's age ( $\geq 14$ years vs younger). These primary care doctors act as gatekeepers to other levels of care. GPs are salaried and their payment is composed of two parts: a larger fixed remuneration and a small one (less than $10 \%$ of total) based on the number of patients assigned to their lists of patients; there are no financial incentives to the physicians for the number of visits they provide nor the fulfilment of objectives, such as restraints in prescriptions expenditure or number of referrals.

In our setting, patients are included in the physicians' lists according to administrative criteria. Geographic proximity to the dwelling is the unique factor for assigning the patient to the health centre. Although, on paper, each patient can choose among the doctors of her/his health centre, actually such an option is very limited and infrequently taken. First, there are no publicly available performance metrics of primary care providers that can guide patient preferences. Besides, patients find restrictions when changing their doctor: in order to achieve equitable workloads, health centres establish rules to distribute patients and each GP is assigned a similar number of persons adjusting by age 
groups. Thus, even though the allocation of patients to doctors is not entirely driven by hazard, it seems very difficult that populations with particular unobserved characteristics were concentred on the lists of some GPs.

Electronic health records, which started to be introduced in 1990, are now used by all primary care doctors.

\section{Study population and period}

The observation period was set at 1 year, from 1 September 2007 to 31 August 2008. The study population included all residents $\geq 14$ years of age who were covered by the public healthcare system in the Basque Country on 31 August 2008 and who had been covered for at least 6 months in the previous year, regardless of whether they had used or had any contact with the Basque Health System (Osakidetza) in that period. That is, almost the entire population of the Basque Country was included.

In this study, we analysed data from across the public health service network: 130 health centres and 1193 GPs. The total number of registered inhabitants was 1 959682 , meaning that the GP lists were composed of a mean of 1643 people.

\section{Sources of data}

We used the two following sources of data:

- Electronic health records of the Basque primary healthcare system, which contain demographic, administrative and clinical data, including diagnoses, prescriptions, ancillary test results and referrals, generated in relation to each patient visit.

- The minimum basic data set, which gathers information on all hospital discharges from across the Basque network of public hospitals, including data on patient characteristics, hospitalisation episodes, diagnoses and procedures.

\section{Variables and statistical analysis}

At the level of the individual patient, we used demographics (age and sex), morbidity and socioeconomic characteristics as explanatory variables.

In order to include a manageable number of diseases, we classified all the patient diagnoses (International Classification of Diseases, Ninth Revision, Clinical Modification (ICD-9-CM) codes) made by the GPs during the study year into Aggregated Diagnosis Groups (ADGs). ${ }^{22}$ The ADG system assigns ICD-9-CM codes to 1 of 32 categories, as a function of clinical criteria, the expected resource use and type of care required for each health problem. It is part of the Johns Hopkins Adjusted Clinical Group (ACG) case-mix system, which is described elsewhere. ${ }^{23}$

As a proxy for the socioeconomic status of patients, we used a deprivation index based on census data, created for the MEDEA ${ }^{24}$ (Mortalidad en áreas pequeñas Españolas y Desigualdades socio-Económicas y Ambientales-Mortality in small Spanish areas and socio-economic and environmental inequalities) project. Census tracts are the smallest territorial units for which census population data are available in Spain and they are mainly defined by criteria related to population size and geographic and social features. Although the number of residents varies between tracts, the median is 1200. For this study, the deprivation index was categorised into five groups, the fifth corresponding to the areas with the greatest deprivation and the first to the least deprived areas. It is an indicator of the socioeconomic status of people living in a community and it has been shown to be correlated with rates of mortality ${ }^{25}$ and morbidity. ${ }^{26}$

At the GP level, to estimate their workload, we considered the number of patients on their list. Using this information, the GP lists were divided into four groups (quartiles), those in the highest quartile being large, those in the second and third quartiles medium-sized and those in the lowest quartile small-sized.

We used a similar approach to characterise the primary care health centres. In this case, the variables used were area-level demographic factors (percentages of people above 65 years of age and of immigrants), ${ }^{27}$ size of the centre (number of GPs on the staff) and level of satisfaction of the centre's staff with their work environment. The last of these variables corresponds to the overall satisfaction score for the health centre, calculated from the results of an internal survey carried out on a regular basis by Osakidetza in all its organisations. ${ }^{28}$ Like GPs, the health centres were categorised into quartiles, the level of satisfaction being rated as high for those in the highest quartile, moderate for those in the middle two quartiles and low for those in the lowest quartile.

All the analysis was performed using SAS V.9.2.

For the first stage of analysis, we considered the following response variables at the patient level: number of visits to the GP, number of forms for referrals to specialists issued by the GP, and costs to the Department of Health of drugs prescribed to the patient during the year of the study.

We constructed multilevel mixed models ${ }^{29}$ to identify which GPs were outliers in terms of resource use. Taking into account the hierarchical nature of the data, we used the explanatory variables as fixed effects and included random intercepts for each of the higher levels: GP, health centre and health district. As a function of the distribution of the response variables, we used different regression models: in the case of prescribing costs, we built a normal regression model (Proc MIXED, RMLE), while for the visits and referrals we used negative binomial regression models (Proc GLIMMIX, LAPLACE). Using an empirical Bayesian approach, ${ }^{30}$ these models allowed us to estimate the differences between the performance of each GP and the mean for each of the response variables, after adjusting for the other variables, as well as $95 \%$ CIs for the estimators. For visits and referrals, the estimators were exponentiated to obtain the incidence rate ratios. We considered doctors to be outliers (high or low) when their estimators statistically differed from zero (prescribing costs) or one (visits and referrals). 
For the second stage, in addition to variables considered in the first stage, we used classifications of each doctor (high/intermediate/low) with respect to their use of healthcare resources (visits, referrals and prescribing costs) as explanatory variables, following the aforementioned procedure, and the appearance of preventable hospitalisations as the response variable. For this purpose, we identified patients who had had one or more admissions attributable to ACSCs, using the list established in Spain by Caminal et al. ${ }^{12}$

Using these variables, we constructed a multilevel mixed-effect logistic regression (Proc GLIMMIX, LAPLACE). In this case, we used the aforementioned explanatory variables (including the GP's classifications by resource use) as fixed effects and a random intercept for each of the three higher levels (GP, health centre and health district). The results are expressed as ORs.

\section{RESULTS}

During the 12 months of the study, $70.2 \%$ of patients made at least one visit to their GP. The annual means per patient were: 4.47 primary care visits, 0.4 referrals and $€ 153.28$ in prescribing costs.

Figure 1 shows the distribution of GPs into the three levels of resource use. The percentages of GPs with higher and lower than expected resource use per patient were as follows: $228(19.1 \%)$ and $140(11.7 \%)$ for visits; $21.1 \%$ and $15.4 \%$ for referrals; and $17.9 \%$ and $16.3 \%$ for prescribing costs, respectively.

A total of 21051 people were admitted one or more times for an ACSC, corresponding to $1.07 \%$ of the total population. ACSC admission rates were associated with demographic characteristics of patients (table 1), though not linearly. On the basis of the crude rates, admissions appeared to increase with age; however, after adjusting for the variables studied including morbidity, we obtained a J-shaped bimodal distribution, with a peak among the youngest people and a higher peak at the oldest ages. With respect to sex, men were more likely to have preventable hospitalisations. As for the deprivation index, more disadvantaged social groups had higher rates of ACSC admissions, although there were only statistically significant differences comparing the most and least disadvantaged populations. Regarding morbidity, in general, we observed that the risk of admission for ACSCs was associated with the diagnostic groups (ADGs) for acute diseases, major symptoms, recurrent health problems (except allergy), chronic diseases and psychosocial problems. However, this was not the case for chronic disorders that often require specialised care, other than mental health (table 2).

With respect to the doctor-level variables (table 3), the risk of ACSC admissions was higher for patients of GPs with a greater than expected mean number of visits and prescribing costs $(\mathrm{OR}=1.29$ (1.21 to 1.37); 1.16 (1.09 to 1.24)) or with a lower than expected mean rate of referrals $(\mathrm{OR}=1.33$ (1.24 to 1.41$))$. The number of patients on the GP's list did not reach statistical significance $(\mathrm{p}=0.0935)$.

In our analysis, none of the health centre characteristics (size, level of satisfaction of staff, and percentages of elderly individuals and of immigrants in the population) reached statistical significance.

\section{DISCUSSION}

\section{Main findings}

Our results indicate that various characteristics of patients and GPs are associated with the risk of hospital admission for potentially preventable conditions. At the patient level, the rate of these admissions was significantly higher in two age groups, the youngest and the oldest patients, in males, and in various groups with acute, recurrent or chronic disorders, as well as those with psychosocial problems; on the other hand, the admission rate was lower in people from the most advantaged socioeconomic status. At the doctor level, once we had adjusted for morbidity and the other variables analysed, the risk of admission for ACSCs was higher in people seen by GPs with greater than expected numbers of visits by patients and prescribing costs and with lower rates of referrals than other doctors. Differences in admissions as a function of variables characterising the health centre (number of GPs; satisfaction with the work environment; percentage of elderly individuals and of immigrants in the population) or GP list size were not statistically significant.

\section{Strengths and limitations}

The main strength of this study is that we analysed data for an entire healthcare system, providing near universal care for the population of a defined geographical area. Further, it assesses the relationship between preventable diseases and variables at different levels, ranked in accordance with the hierarchical nature of the data, as well as compares the risk of admission of patients seen by doctors with different clinical practice patterns. In addition, we used a robust system for adjusting for patient morbidity, namely the Johns Hopkins ACG case-mix system.

However, we should also recognise some limitations. First, the data analysed come from the daily records entered in the health information system of the Basque Country and, as is commonly the case with the use of administrative databases and electronic health records, there may be some incomplete or inaccurate data. Second, the ecological nature of the socioeconomic variable used (deprivation index) might have diluted the effect of individual socioeconomic characteristics; it is also known that social factors other than the ones studied have an effect on the need for healthcare and its outcomes. ${ }^{31}$ Similarly, other characteristics of patients (such as health services-seeking preferences, unmeasured health status or treatment adherence) were not observed. Further, this paper is focused on the organisation of public health service provision and planning, and thus private health provision is beyond the scope of our analysis. 

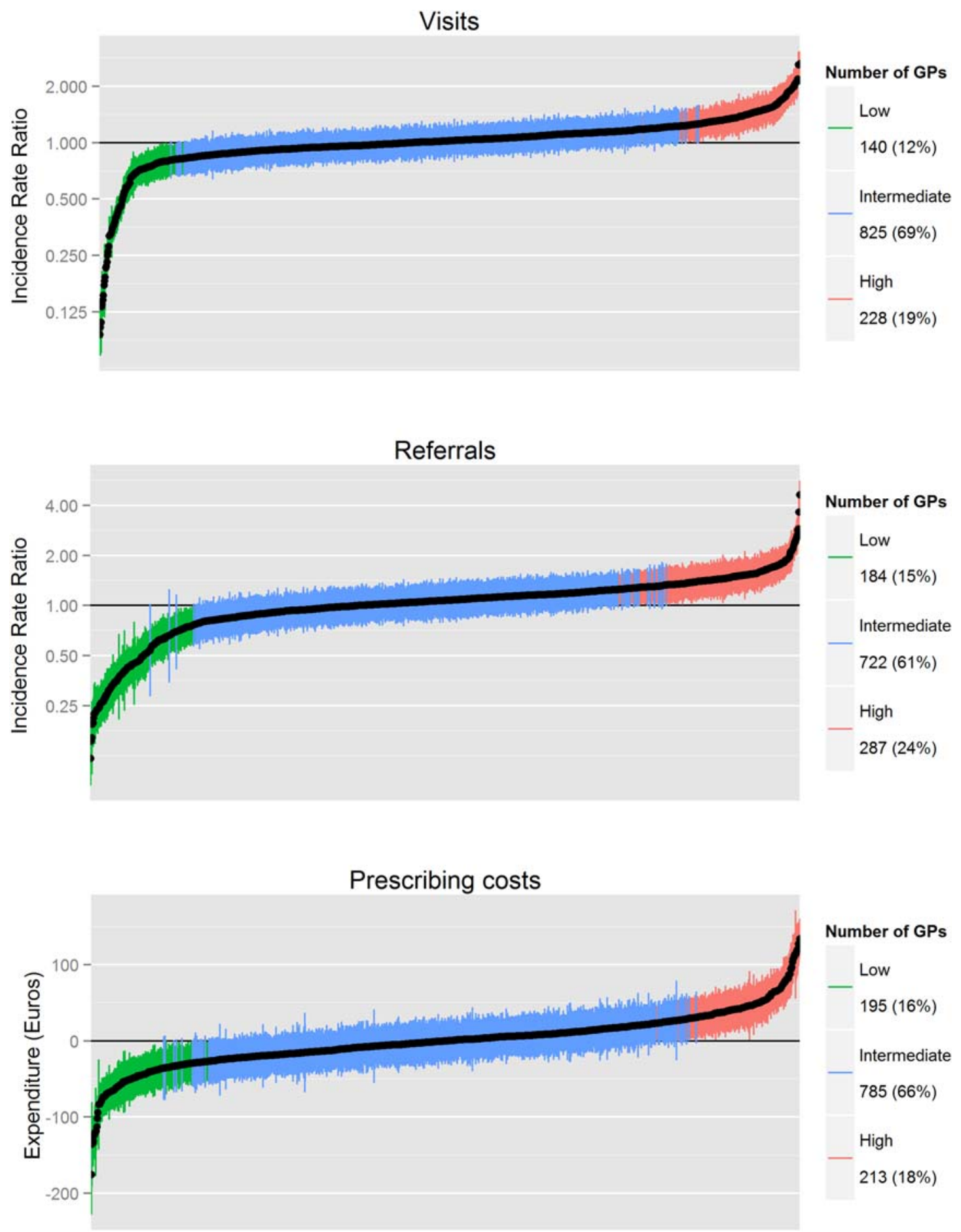

Figure 1 Relative consumption of resources by the 1193 general practitioners (GPs), by rank from lowest to highest. Difference with respect to an average GP expressed as ratios (visits, referrals) or in absolute value (prescribing costs). Vertical bars correspond to $95 \%$ Cls.

With respect to the definition of ACSCs, it should be taken into account that there are factors unrelated to primary care itself that could have an effect on hospital admissions. The use of a list of conditions adapted for our setting (in this case, Spain) has advantages from the point of view of the validity of our results, but it may make it difficult to generalise the findings to other areas. Additionally, in relation to external validity, Spain has primary care health services that are well established and easy to access by the population, ${ }^{32}$ with higher rates of visits to doctors and generally lower rates of ACSC admissions than reported for other settings. ${ }^{33}$ Hence, it might not be possible to extrapolate our findings to other settings with different characteristics.

\section{Comparison with other studies}

Our results are partially consistent with previous research. Various different authors have established that 
Table 1 Multilevel analysis

\begin{tabular}{|c|c|c|c|c|}
\hline & $\begin{array}{l}\text { Number of } \\
\text { patients }\end{array}$ & $\begin{array}{l}\text { Number of patients } \\
\text { with } \geq 1 \text { ACSC }\end{array}$ & OR & $\begin{array}{l}\text { Likelihood } \\
\text { ratio test }\end{array}$ \\
\hline Total & 1959682 & 21051 (1.07\%) & & \\
\hline Age groups (years) & & & & $<0.0001$ \\
\hline $14-24$ & 196804 & 564 (0.29\%) & Reference & \\
\hline $25-34$ & 351095 & $1090(0.31 \%)$ & 0.92 (0.81 to 1.02$)$ & \\
\hline $35-44$ & 381810 & $1411(0.37 \%)$ & 0.77 (0.66 to 0.87$)$ & \\
\hline $45-54$ & 330703 & $1897(0.57 \%)$ & $0.71(0.60$ to 0.81$)$ & \\
\hline $55-64$ & 274850 & 2851 (1.04\%) & 0.68 (0.58 to 0.78$)$ & \\
\hline $65-69$ & 100891 & $1576(1.56 \%)$ & 0.65 (0.54 to 0.76$)$ & \\
\hline $70-74$ & 101478 & 2379 (2.34\%) & 0.74 (0.64 to 0.85$)$ & \\
\hline $75-79$ & 95636 & 3257 (3.41\%) & 0.85 (0.75 to 0.95$)$ & \\
\hline $80-84$ & 67296 & $3092(4.59 \%)$ & $1.03(0.93$ to 1.14$)$ & \\
\hline $85+$ & 59119 & 2934 (4.96\%) & 1.38 (1.28 to 1.49$)$ & \\
\hline Sex & & & & $<0.0001$ \\
\hline Male & 955138 & $11990(1.26 \%)$ & $1.41(1.37$ to 1.44$)$ & \\
\hline Female & 1004544 & $9061(0.90 \%)$ & Reference & \\
\hline Deprivation index & & & & 0.0139 \\
\hline 1 & 390386 & 2995 (0.77\%) & $0.92(0.85$ to 0.99$)$ & \\
\hline 2 & 387231 & 4041 (1.04\%) & $1.02(0.96$ to 1.08$)$ & \\
\hline 3 & 394884 & 4375 (1.11\%) & 0.99 (0.93 to 1.05$)$ & \\
\hline 4 & 391844 & $4678(1.19 \%)$ & 0.97 (0.92 to 1.03$)$ & \\
\hline 5 & 395337 & $4962(1.26 \%)$ & Reference & \\
\hline
\end{tabular}

ACSC admissions are associated with certain individualbased factors including being male, ${ }^{14} 34{ }^{35}$ being elderly, ${ }^{16} 35$ having a low socioeconomic status, ${ }^{15} 192036$ being from disadvantaged ethnic or racial groups, ${ }^{20} 37$ and having chronic diseases ${ }^{17} 1838$ or mental health problems. $^{39} 40$ However, our results differ from those of other authors such as Casalino et $a l^{41}$ who found an inverse relationship between the size of primary healthcare teams and ACSC admissions. What is more, associations with factors related to access to primary care health services that have often been described, such as an inverse correlation between ACSC admissions and the patient-to-doctor ratio, ${ }^{3}{ }^{21}$ were also not found in our data. Although some authors have assessed the relationship between ACSC admissions and the number of visits to GPs by patients ${ }^{3} 3842-44$ and even the mean daily number of consultations held by doctors in a geographical area, ${ }^{15}$ we are not aware of any studies similar to ours. In particular, we studied the association between potentially preventable admissions and efficiency indicators of GPs based on the ratio between the observed and expected consumption of resources: number of visits by patients, referrals and prescribing costs.

\section{Significance of the study: potential explanations and implications for doctors and managers}

Although it is not possible to demonstrate causal correlations from an observational study as ours, our analysis suggest that certain clinical practice patterns of primary care doctors have an effect on the outcomes of care. In particular, we have observed that in GPs holding a more than expected number of visits with patients, higher prescribing costs or a lower referrals rate is associated with higher rates of preventable admissions.

In our opinion, physicians' practice styles may play a central role and a plausible hypothesis is that some doctors try to avoid referrals, and due to that their patients need more prescriptions and following visits to GP; conceivably, this sequence might generate some inappropriate accessibility to specialised care for patients.

Other alternative explanations (such as populations with particular unobserved characteristics being concentred on the lists of some GPs or that patients after a hospital discharge due to ACSC seek GPs' attention but elude being referred to specialised care) seem unlikely. Physician training can influence referral decisionmaking, but in the Basque Country most of the GPs have completed the Family Medicine Residency Program and only a very scarce number of doctors are not family physicians. GPs are not allowed to make choices about the specialist to whom they refer their patients nor receive additional compensations for referrals. Even though there are GPs working in rural and urban locations in our setting, the uneven distribution of specialists between geographic areas has not affected our results, since health centre random effects are included in the estimations.

The benefits of primary care on the health of people and populations have been demonstrated and widely recognised. ${ }^{2}$ Other authors have described the added value to the care of a generalist approach, especially for patients with complex multimorbidity, this giving rise to the paradox that GPs provide poorer quality healthcare than specialists in the treatment of specific diseases, but 
Table 2 Multilevel analysis

\begin{tabular}{|c|c|c|c|c|}
\hline Aggregated diagnosis groups & $\begin{array}{l}\text { Number of } \\
\text { patients }\end{array}$ & $\begin{array}{l}\text { Number of patients } \\
\text { with } \geq 1 \text { ACSC }\end{array}$ & OR & $\begin{array}{l}\text { Likelihood } \\
\text { ratio test }\end{array}$ \\
\hline 1. Time limited: minor & 245892 & 4904 (1.99\%) & $0.98(0.94$ to 1.02$)$ & 0.4445 \\
\hline 2. Time limited: minor-primary infections & 535848 & $12363(2.31 \%)$ & $1.92(1.89$ to 1.96$)$ & $<0.0001$ \\
\hline 3. Time limited: major & 48055 & $6275(13.06 \%)$ & 3.40 (3.35 to 3.44$)$ & $<0.0001$ \\
\hline 4. Time limited: major-primary infections & 50853 & $6642(13.06 \%)$ & $5.34(5.3$ to 5.38$)$ & $<0.0001$ \\
\hline 5. Allergies & 52289 & $683(1.31 \%)$ & $0.93(0.84$ to 1.02$)$ & 0.1174 \\
\hline 6. Asthma & 44212 & 2040 (4.61\%) & 3.29 (3.23 to 3.35$)$ & $<0.0001$ \\
\hline 7. Likely to recur: discrete & 265298 & $6936(2.61 \%)$ & $1.15(1.12$ to 1.19$)$ & $<0.0001$ \\
\hline 8. Likely to recur: discrete-infections & 153097 & $4966(3.24 \%)$ & $2.06(2.02$ to 2.1$)$ & $<0.0001$ \\
\hline 9. Likely to recur: progressive & 37633 & $7762(20.63 \%)$ & 5.57 (5.53 to 5.61$)$ & $<0.0001$ \\
\hline 10. Chronic medical: stable & 463513 & $16291(3.51 \%)$ & 2.64 (2.6 to 2.69$)$ & $<0.0001$ \\
\hline 11. Chronic medical: unstable & 151413 & $15164(10.01 \%)$ & 7.78 (7.74 to 7.82$)$ & $<0.0001$ \\
\hline 12. Chronic specialty: stable_-orthopaedic & 35199 & $1418(4.03 \%)$ & $1.09(1.02$ to 1.16$)$ & 0.0163 \\
\hline 13. Chronic specialty: stable-ear, nose, throat & 22348 & $540(2.42 \%)$ & $0.92(0.81$ to 1.02$)$ & 0.1152 \\
\hline 14. Chronic specialty: stable-eye & 38059 & $1161(3.05 \%)$ & $0.84(0.76$ to 0.91$)$ & $<0.0001$ \\
\hline 16. Chronic specialty: unstable-orthopaedic & 12006 & $350(2.92 \%)$ & $0.88(0.75$ to 1.02$)$ & 0.0736 \\
\hline $\begin{array}{l}\text { 17. Chronic specialty: unstable-ear, nose, } \\
\text { throat }\end{array}$ & 2180 & $70(3.21 \%)$ & $2.02(1.72$ to 2.31$)$ & $<0.0001$ \\
\hline 18. Chronic specialty: unstable-eye & 33479 & $1343(4.01 \%)$ & $0.99(0.92$ to 1.06$)$ & 0.7590 \\
\hline 20. Dermatological & 98720 & $1451(1.47 \%)$ & $0.84(0.77$ to 0.9$)$ & $<0.0001$ \\
\hline 21. Injuries/adverse effects: minor & 78973 & $1760(2.23 \%)$ & $0.90(0.84$ to 0.96$)$ & 0.001 \\
\hline 22. Injuries/adverse effects: major & 79568 & $3490(4.39 \%)$ & $1.11(1.06$ to 1.16$)$ & $<0.0001$ \\
\hline 23. Psychosocial: time limited, minor & 71206 & $3563(5.00 \%)$ & 2.09 (2.04 to 2.14$)$ & $<0.0001$ \\
\hline 24. Psychosocial: recurrent or persistent, stable & 104605 & $2872(2.75 \%)$ & $1.08(1.02$ to 1.13$)$ & 0.0055 \\
\hline $\begin{array}{l}\text { 25. Psychosocial: recurrent or persistent, } \\
\text { unstable }\end{array}$ & 30667 & $2303(7.51 \%)$ & $1.77(1.71$ to 1.83$)$ & $<0.0001$ \\
\hline 26. Signs/symptoms: minor & 281636 & $6227(2.21 \%)$ & $0.87(0.83$ to 0.91$)$ & $<0.0001$ \\
\hline 27. Signs/symptoms: uncertain & 391194 & 9869 (2.52\%) & $1.15(1.11$ to 1.18$)$ & $<0.0001$ \\
\hline 28. Signs/symptoms: major & 164059 & 8095 (4.93\%) & $1.60(1.56$ to 1.64$)$ & $<0.0001$ \\
\hline 29. Discretionary & 150922 & 4324 (2.87\%) & $1.01(0.97$ to 1.06$)$ & 0.5712 \\
\hline 30. See and reassure & 27910 & 1247 (4.47\%) & $1.20(1.12$ to 1.27$)$ & $<0.0001$ \\
\hline 31. Preventive/administrative & 851425 & 17603 (2.07\%) & $1.61(1.57$ to 1.66$)$ & $<0.0001$ \\
\hline 32. Malignancy & 28033 & $1643(5.86 \%)$ & $0.92(0.85$ to 0.99$)$ & 0.0208 \\
\hline 33. Pregnancy & 31130 & 159 (0.51\%) & $1.01(0.84$ to 1.19$)$ & 0.8965 \\
\hline 34. Dental & 52218 & $793(1.52 \%)$ & 0.91 (0.82 to 0.99$)$ & 0.0248 \\
\hline
\end{tabular}

achieve better outcomes in the overall health of people and populations. ${ }^{45}$

However, as in other healthcare contexts, doing more is not always better in primary care. On the basis of our results, we can state that GPs performing an excessive number of visits with patients present higher rates of preventable admissions, as is GPs having higher prescribing costs, while those who play the role of strong "gatekeepers" and are more reluctant to "pass the baton" to specialists also achieve poorer results.

Accordingly, indicators that measure the performance of health professionals should be interpreted with caution, unless they are accompanied by other indicators of care outcomes. Otherwise, interventions focused on modifying clinical practice patterns may have undesired consequences. On the other hand, from a health policy perspective, our results can assist the idea that excessive fragmentation between healthcare levels could result in detriments to the population's health. In contrast, the assumption of shared values and objectives by primary and specialised care can aid a seamless, coordinated and person-centred assistance.

\section{Unanswered questions and future research}

This study indicates how certain ways of working among primary care doctors are associated with different outcomes in terms of preventable hospitalisation of patients. However, it does not allow us to establish the causes of these differences. Visits to GPs are diverse in nature: they may occur on the initiative of the patient or of the doctor; they have many underlying reasons (eg, for assessing symptoms or diseases, social problems, provision of advice or administrative procedures); and they may vary in terms of duration, structure, procedures performed and the involvement of other primary care health professionals, such as nurses. Several factors increase prescribing costs: excessive prescribing, inappropriate treatments and selection of the most 
Table 3 Multilevel analysis

\begin{tabular}{|c|c|c|c|c|}
\hline & $\begin{array}{l}\text { Number of } \\
\text { patients }\end{array}$ & $\begin{array}{l}\text { Number of patients } \\
\text { with } \geq 1 \text { ACSC }\end{array}$ & OR & $\begin{array}{l}\text { Likelihood } \\
\text { ratio test }\end{array}$ \\
\hline \multicolumn{5}{|c|}{ Characteristics of the GP } \\
\hline \multicolumn{4}{|c|}{ List size } & 0.0935 \\
\hline Large & 387451 & $3594(0.93 \%)$ & 0.96 (0.87 to 1.05$)$ & \\
\hline Medium & 1180860 & $12950(1.10 \%)$ & Reference & \\
\hline Small & 391371 & 4507 (1.15\%) & $0.92(0.84$ to 1.00$)$ & \\
\hline \multicolumn{4}{|c|}{ Frequency of patient visits } & $<0.0001$ \\
\hline High & 356361 & $3592(1.01 \%)$ & $1.29(1.21$ to 1.37$)$ & \\
\hline Intermediate & 1382634 & $15128(1.09 \%)$ & Reference & \\
\hline Low & 220678 & $2331(1.05 \%)$ & 1.08 (0.99 to 1.17$)$ & \\
\hline \multicolumn{4}{|l|}{ Rate of referral } & $<0.0001$ \\
\hline High & 485792 & 5005 (1.03\%) & 1.02 (0.95 to 1.09$)$ & \\
\hline Intermediate & 1175905 & $13031(1.11 \%)$ & Reference & \\
\hline Low & 297985 & 3015 (1.01\%) & $1.33(1.24$ to 1.41$)$ & \\
\hline \multicolumn{4}{|l|}{ Prescribing costs } & 0.0003 \\
\hline High & 349560 & $3836(1.10 \%)$ & 1.16 (1.09 to 1.24$)$ & \\
\hline Intermediate & 1298466 & 13823 (1.07\%) & Reference & \\
\hline Low & 311656 & $3836(1.09 \%)$ & 1.02 (0.94 to 1.09$)$ & \\
\hline \multicolumn{5}{|c|}{ Characteristics of the primary care centre } \\
\hline \multicolumn{5}{|l|}{ centre } \\
\hline Large & 370318 & $3561(0.96 \%)$ & $1.03(0.86$ to 1.21$)$ & \\
\hline Medium & 1269509 & $13914(1.10 \%)$ & Reference & \\
\hline Small & 319855 & $3576(1.12 \%)$ & $0.94(0.81$ to 1.07$)$ & \\
\hline \multicolumn{4}{|l|}{ Staff satisfaction } & 0.6945 \\
\hline High & 389948 & $4531(1.16 \%)$ & $0.99(0.86$ to 1.12$)$ & \\
\hline Intermediate & 1187944 & $12844(1.08 \%)$ & Reference & \\
\hline Low & 381790 & $3676(0.96 \%)$ & $0.94(0.80$ to 1.08$)$ & \\
\hline \multicolumn{4}{|c|}{ Percentage of immigrants in the population } & 0.9170 \\
\hline High & 393285 & $4754(1.21 \%)$ & $0.98(0.83$ to 1.14$)$ & \\
\hline Intermediate & 1173120 & $12045(1.03 \%)$ & Reference & \\
\hline Low & 393277 & $4252(1.08 \%)$ & $1.02(0.89$ to 1.16$)$ & \\
\hline \multicolumn{4}{|c|}{ Percentage of elderly individuals in the population } & 0.5818 \\
\hline High & 389721 & $4474(1.15 \%)$ & $1.02(0.89$ to 1.16$)$ & \\
\hline Intermediate & 1186379 & $12927(1.09 \%)$ & Reference & \\
\hline Low & 383582 & $3650(0.95 \%)$ & $1.08(0.93$ to 1.23$)$ & \\
\hline
\end{tabular}

expensive option. Important factors regarding referrals are whether they are appropriate and timely, as well as the type of specialist patients are referred to, and the subsequent level of coordination between the GP and the specialist in the shared management of the patient. In relation to this, there is a need for future studies analysing primary care outcomes that consider other factors related to visits, referrals and prescriptions. Furthermore, our results should be tested in other settings or specific population groups (eg, patients with multimorbidity or with specific diseases). In any case, our findings provide a starting point for discussion and research concerning what should be the limits in terms of the "quantity" of primary care provided to meet the needs of the population.

Acknowledgements The authors thank the MEDEA research team in the Basque Country for the calculation and provision of the deprivation index. At the same time, they want to explicitly thank Montse Calvo for her work in geocodifying the data.
Contributors JFO and GG contributed in the design of the study. JFO performed the validation of the databases. AGA and GG were responsible for statistical analyses. JFO wrote the draft of the manuscript. All the authors participated in the interpretation of the data; they also critically reviewed and gave final approval to the manuscript.

Funding A grant (10/00319) from Fondo de Investigación Sanitaria was received in support of this project (Healthcare Research Fund of the Carlos III Health Institute. Spanish Ministry of Health, Social Services and Equality). This paper presents an independent research partially funded by Fondo de Investigación Sanitaria.

Competing interests None declared.

Ethics approval The Clinical Research Ethics Committee of the Basque Country approved this study (PI2012151).

Provenance and peer review Not commissioned; externally peer reviewed. Data sharing statement No additional data are available.

Open Access This is an Open Access article distributed in accordance with the Creative Commons Attribution Non Commercial (CC BY-NC 4.0) license, which permits others to distribute, remix, adapt, build upon this work noncommercially, and license their derivative works on different terms, provided 
the original work is properly cited and the use is non-commercial. See: http:// creativecommons.org/licenses/by-nc/4.0/

\section{REFERENCES}

1. The King's Fund. Improving the quality of care in English general practice: a report of an independent inquiry commissioned by The King's Fund. London: The King's Fund, 2011.

2. Starfield B, Shi L, Macinko J. Contribution of primary care to health systems and health. Milbank Q 2005;83:457-502.

3. Rizza P, Bianco A, Pavia M, et al. Preventable hospitalization and access to primary health care in an area of Southern Italy. BMC Health Serv Res 2007;7:134

4. Trivedi AN, Moloo H, Mor V. Increased ambulatory care copayments and hospitalizations among the elderly. N Engl J Med 2010;362:320-8.

5. Fleetcroft R, Cookson R, Steel N, et al. Correlation between prescribing quality and pharmaceutical costs in English primary care: national cross-sectional analysis. Br J Gen Pract 2011;61:e556-64.

6. Arnold SR, Straus SE. Interventions to improve antibiotic prescribing practices in ambulatory care. Cochrane Database Syst Rev 2005;(4): CD003539.

7. Keyhani S, Falk R, Howell EA, et al. Overuse and systems of care: a systematic review. Med Care 2013;51:503-8.

8. Stuart BC, Doshi JA, Terza JV. Assessing the impact of drug use on hospital costs. Health Serv Res 2009;44:128-44.

9. Austvoll-Dahlgren A, Aaserud M, Vist G, et al. Pharmaceutical policies: effects of cap and co-payment on rational drug use. Cochrane Database Syst Rev 2008;(1):CD007017.

10. Agency for Healthcare Research and Quality. Guide to prevention quality indicators: hospital admission for ambulatory care sensitive conditions. 2007. http://qualityindicators.ahrq.gov/downloads/modules/ pqi/v31/pqi_technical_specs_v31.pdf (accessed 4 Nov 2014).

11. Purdy S, Griffin T, Salisbury C, et al. Ambulatory care sensitive conditions: terminology and disease coding need to be more specific to aid policy makers and clinicians. Public Health 2009;123:169-73.

12. Caminal J, Starfield B, Sánchez E, et al. The role of primary care in preventing ambulatory care sensitive conditions. Eur J Public Health 2004;14:246-51.

13. Bermúdez-Tamayo $\mathrm{C}$, Márquez-Calderón $\mathrm{S}$, Rodríguez del Aguila $\mathrm{MM}$, et al. [Organizational characteristics of primary care and hospitalization for to the main ambulatory care sensitive conditions]. Aten Primaria 2004;33:305-11.

14. Magan $P$, Otero A, Alberquilla $A$, et al. Geographic variations in avoidable hospitalizations in the elderly, in a health system with universal coverage. BMC Health Serv Res 2008;8:42.

15. Magán $P$, Alberquilla A, Otero A, et al. Hospitalizations for ambulatory care sensitive conditions and quality of primary care: their relation with socioeconomic and health care variables in the Madrid regional health service (Spain). Med Care 2011;49:17-23.

16. Bardsley M, Blunt I, Davies S, et al. Is secondary preventive care improving? Observational study of 10-year trends in emergency admissions for conditions amenable to ambulatory care. BMJ Open 2013;3:pii:e002007.

17. Wolff JL, Starfield B, Anderson G. Prevalence, expenditures, and complications of multiple chronic conditions in the elderly. Arch Intern Med 2002;162:2269-76.

18. Saver BG, Wang C-Y, Dobie SA, et al. The central role of comorbidity in predicting ambulatory care sensitive hospitalizations. Eur J Public Health 2014;24:66-72.

19. Roos LL, Walld R, Uhanova J, et al. Physician visits, hospitalizations, and socioeconomic status: ambulatory care sensitive conditions in a Canadian setting. Health Serv Res 2005;40:1167-85.

20. Moy E, Chang E, Barrett M, et al. Potentially preventable hospitalizations-United States, 2001-2009. MMWR Surveill Summ 2013;62(Suppl 3):139-43.

21. Laditka JN, Laditka SB, Probst JC. More may be better: evidence of a negative relationship between physician supply and hospitalization for ambulatory care sensitive conditions. Health Serv Res 2005:40:1148-66.

22. Weiner JP, Starfield BH, Steinwachs DM, et al. Development and application of a population-oriented measure of ambulatory care case-mix. Medical Care 1991;29:452-72.
23. Johns Hopkins University, School of Public Health. The Johns Hopkins University ACG case-mix system. http://acg.jhsph.org/index php?option=com_content $\&$ view $=$ article\&id=46\&Itemid $=366$ (accessed 4 Nov 2014)

24. Domínguez-Berjón MF, Borrell C, Cano-Serral G, et al. [Constructing a deprivation index based on census data in large Spanish cities(the MEDEA project)]. Gac Sanit 2008:22:179-87.

25. Borrell C, Marí-Dell'olmo M, Serral G, et al. Inequalities in mortality in small areas of eleven Spanish cities (the multicenter MEDEA project). Health Place 2010;16:703-11.

26. Orueta JF, Nuño-Solinís R, García-Alvarez A, et al. Prevalence of multimorbidity according to the deprivation level among the elderly in the Basque Country. BMC Public Health 2013;13:918.

27. Eustat (Instituto Vasco de Estadística). Population statistics. VitoriaGasteiz: 2004. http://en.eustat.es/estadisticas/tema_159/opt_0/ti Population/temas.html\#axzz37p2gs8HG (accessed 4 Nov 2014).

28. Osakidetza Comarca Uribe. Satisfacción de las personas. Comarca Uribe: 2010. http://uribe.osakidetza.net/es/html/4/2123.shtml (accessed 4 Nov 2014).

29. Raudenbush SW, Bryk AS. Hierarchical linear models: applications and data analysis methods. SAGE Publications, 2002.

30. Snijders TAB, Bosker RJ. Multilevel analysis: an introduction to basic and advanced multilevel modeling. Sage Publications, 1999.

31. Rosen AK, Reid R, Broemeling A-M, et al. Applying a risk-adjustment framework to primary care: can we improve on existing measures? Ann Fam Med 2003;1:44-51.

32. Kringos D, Boerma $W$, Bourgueil $Y$, et al. The strength of primary care in Europe: an international comparative study. Br J Gen Pract 2013;63:e742-50.

33. OECD. Health at a Glance 2013. Paris: Organisation for Economic Co-operation and Development, 2013. http://www.oecd-ilibrary.org/; jsessionid=4ho9u8gumc0h9.x-oecd-live-02content/book/health_ glance-2013-en (accessed 4 Nov 2014).

34. Stranges E, Stocks C. Potentially preventable hospitalizations for acute and chronic conditions, 2008: Statistical Brief \#99. In: Healthcare Cost and Utilization Project (HCUP) Statistical Briefs. Rockville, MD: Agency for Health Care Policy and Research (US), 2006. http://www.ncbi.nlm.nih.gov/books/NBK52655/ (accessed 29 Oct 2014).

35. Ansari Z, Haider SI, Ansari H, et al. Patient characteristics associated with hospitalisations for ambulatory care sensitive conditions in Victoria, Australia. BMC Health Serv Res 2012;12:475.

36. Giuffrida A, Gravelle $H$, Roland M. Measuring quality of care with routine data: avoiding confusion between performance indicators and health outcomes. BMJ 1999;319:94-8.

37. O'Neil SS, Lake T, Merrill A, et al. Racial disparities in hospitalizations for ambulatory care-sensitive conditions. Am J Prev Med 2010;38:381-8.

38. Eggli Y, Desquins B, Seker E, et al. Comparing potentially avoidable hospitalization rates related to ambulatory care sensitive conditions in Switzerland: the need to refine the definition of health conditions and to adjust for population health status. BMC Health Serv Res 2014;14:25.

39. Himelhoch S, Weller WE, Wu AW, et al. Chronic medical illness, depression, and use of acute medical services among Medicare beneficiaries. Med Care 2004;42:512-21.

40. Yoon J, Yano EM, Altman L, et al. Reducing costs of acute care for ambulatory care-sensitive medical conditions: the central roles of comorbid mental illness. Med Care 2012;50:705-13.

41. Casalino LP, Pesko MF, Ryan AM, et al. Small primary care physician practices have low rates of preventable hospital admissions. Health Aff (Millwood) 2014;33:1680-8.

42. Rosano A, Loha CA, Falvo R, et al. The relationship between avoidable hospitalization and accessibility to primary care: a systematic review. Eur J Public Health 2013;23:356-60.

43. Gibson OR, Segal L, McDermott RA. A systematic review of evidence on the association between hospitalisation for chronic disease related ambulatory care sensitive conditions and primary health care resourcing. BMC Health Serv Res 2013;13:336.

44. Gao J, Moran E, Li Y-F, et al. Predicting potentially avoidable hospitalizations. Med Care 2014;52:164-71.

45. Stange KC, Ferrer RL. The paradox of primary care. Ann Fam Med 2009;7:293-9. 